\title{
Erratum to: The IMPACT prognosis calculator used in patients with severe traumatic brain injury treated with an ICP-targeted therapy
}

\author{
Magnus Olivecrona - Lars-Owe D. Koskinen
}

Published online: 12 August 2012

(C) Springer-Verlag 2012

\section{Erratum to: Acta Neurochirurgica}

$$
\text { DOI 10.1007/s00701-012-1351-Z }
$$

The article contains two errors.

The first is found in the Conclusion section of the Abstract: The second last sentence reads: "We conclude that we have to initiate treatment in all patients with blunt sTBI and an initial ICP $>10$ mmHg."

This sentence should read: "We conclude that we have to initiate treatment in all patients with blunt sTBI and an initial cerebral perfusion pressure (CPP) $\geq 10 \mathrm{mmHg}$."

In analogy with this the second error is found in the Materials and methods section's last sentence; which reads: "Patients with dilated, fixed pupils and/or GCS 3 were included provided that their first measured ICP was 10 mmHg or higher".

This sentence should read: "Patients with dilated, fixed pupils and/or GCS 3 were included provided that their first measured $\underline{\text { CPP }}$ was $10 \mathrm{mmHg}$ or higher"

The online version of the original article can be found at http://dx.doi.org/ 10.1007/s00701-012-1351-z.

M. Olivecrona $\cdot$ L.-O. D. Koskinen

Department of Pharmacology and Clinical Neuroscience,

Neurosurgery, Umeå University,

Umeå, Sweden

L.-O. D. Koskinen

e-mail: lars-owe.koskinen@neuro.umu.se

M. Olivecrona $(\bowtie)$

Department of Neurosurgery, Umeå University,

SE 90185 Umeå, Sweden

e-mail: magnus.olivecrona@neuro.umu.se 